\title{
Formation and characterization of neutral krypton and xenon hydrides in low-temperature matrices
}

\author{
Jan Lundell, Leonid Khriachtchev, Mika Pettersson, and Markku Räsänen \\ Laboratory of Physical Chemistry, University of Helsinki, P. O. Box 55 (A. I. Virtasen aukio 1), \\ FIN-00014 University of Helsinki, Finland \\ E-mail: Markku.Rasanen@helsinki.fi \\ Received March 9, 2000
}

\begin{abstract}
A family of rare-gas containing hydrides $\mathrm{HXY}$ (where $\mathrm{X}=\mathrm{Kr}$ or $\mathrm{Xe}, \mathrm{Y}$ is an electronegative fragment) is described. These molecules are experimentally prepared in low-temperature matrices by photodissociation of a hydrogen-containing HY precursor and thermal mobilization of the photodetached hydrogen atoms. The neutral HXY molecules are formed in a concerted reaction $\mathrm{H}+\mathrm{Y} \rightarrow \mathrm{HXY}$. Experimental evidence for the formation of these species is essentially based on strong infrared absorption bands that appear after annealing of the photolyzed matrices and are assigned to the $\mathrm{X}-\mathrm{H}$ stretch of the HXY molecules. Computationally, the formation of these HXY molecules decreases the $\mathrm{H}-\mathrm{X}$ distance by a factor of $\geq 2$ from its van der Waals value, which emphasizes their true chemical bounding possessing both covalent and ionic contributions. The estimated dissociation energies vary from 0.4 to $1.4 \mathrm{eV}$ and keep promises for forthcoming observation of these molecules in the gas phase. The experiments with the HXY molecules widen our knowledge on solid-state photolysis dynamics of hydrogen containing species. In particular, the photolysis of small HY hydrides in solid Xe seems to be a quite local process, and accompanied losses of $\mathrm{H}$ atoms play a minor role.
\end{abstract}

PACS: $82.50 . \mathrm{Fv}$

\section{Introduction}

The rare gas atoms have generally been regarded as inert due to their stable electron structure rejecting chemical bond formation capabilities. However, already in 1933 Pauling suggested, based on the consideration of the ionic radii of different elements, that xenon and krypton were capable of forming neutral chemical compounds especially with fluorine [1]. It took three decades before Bartlett was able to make the first rare gas compound [2]. This molecule constituted an ionic $\mathrm{Xe}^{+}\left[\mathrm{PtF}_{6}\right]^{-}$crystal, which was later shown to consist most probably of a mixture of $\mathrm{XeF}^{+} \mathrm{PtF}_{6}^{-}$and $\mathrm{XeF}^{+} \mathrm{Pt}_{2} \mathrm{~F}_{11}^{-}$[3]. Simultaneously with Bartlett's discovery, Hoppe and coworkers were able to isolate $\mathrm{XeF}_{2}$ [4], and slightly thereafter Claassen et al. prepared $\mathrm{XeF}_{4}$ [5]. These pioneering findings boosted an enthusiastic research on rare gas containing molecules and several xenon compounds, where Xe was bound to fluorine or oxygen, were reported and reviewed extensively later on [6-16]. The theory of Xe-binding has been authoritatively discussed by Coulson [17].
Neutral xenon-chemistry has been enriched constantly, and several xenon-containing species of similar ionic nature to those of Bartlett's first report have been characterized. The first $\mathrm{Xe}-\mathrm{N}$ bond was found in $\mathrm{FXeN}\left(\mathrm{SO}_{2} \mathrm{~F}\right)_{2}$ by LeBlond and DesMarteau [18] and many similar but more complex compounds have been characterized since [1926]. Neutral $\mathrm{FXeCF}_{3}$ and $\mathrm{Xe}\left(\mathrm{CF}_{3}\right)_{2}$ have been discussed in the literature [27-29], but neither of them have been spectroscopically characterized. A stable $\mathrm{Xe}-\mathrm{C}$ bonded molecule, fluorophenylxenon (II) fluoroborate $\left(\left[\mathrm{C}_{6} \mathrm{H}_{5} \mathrm{Xe}\right]\left[\mathrm{B}\left(\mathrm{C}_{6} \mathrm{H}_{5}\right)_{3} \mathrm{~F}\right]\right)$ was reported in 1989 [30] and a number of organoxenonium compounds have been prepared [31,32]. The latest molecule to join the family of organic $\mathrm{Xe}$ compounds is $\mathrm{C}_{6} \mathrm{H}_{5} \mathrm{XeF}_{2}^{+} \mathrm{BF}_{4}^{-}$reported in early 2000 by Frohn and coworkers [33]. The chemistry of fluorine-containing rare gas compounds has been recently thoroughly reviewed by Holloway and Hope [34]. Chemistry of krypton is much more sparse than that of Xe. The first Kr-bonds were found in fluorine containing compounds $\mathrm{KrF}_{2}$ [35-37] and $\mathrm{KrF}_{4}$ [38] in analogy to xenon. In addition, krypton is known to bind with nitrogen and oxygen, and 
these studies have been pioneered by the Schrobilgen group [39-42]. Besides the neutral $\mathrm{Xe}$ - and $\mathrm{Kr}$-containing compounds, a large number of ionic rare gas species have been predicted and found, and the reader is encouraged to look, for example, in Refs. 43-47.

The first characterization of $\mathrm{KrF}_{2}$ and $\mathrm{KrF}_{4}$ took especially advantage of low-temperature matrix isolation technique, which was originally developed to study unstable molecules and reaction intermediates [48-50]. A studied substance is deposited in large dilution with inert gases on a cold surface or generated photochemically in situ from a precursor molecule already deposited. The solid rare gas environment is regarded as inert towards chemical bond formation and the cage effect is employed to isolate the studied chemical system. Further examples of rare gas containing molecules account, for example, $\mathrm{XeCl}_{2}$ [51], $\mathrm{XeClF}[37,52]$ and $\mathrm{FXeBF}_{2}$ [53]

Evidently the formation of such molecules makes the inertness of the solid rare gases questionable and, indeed, recent reviews of photochemical processes in low-temperature matrices underline the interaction between molecular species with the environment upon irradiation [54,55]. These interactions and their consequences on dynamics and chemistry will be discussed in this review, and we will describe solid state synthesis of several $\mathrm{HKrY}$ and $\mathrm{HXeY}$ ( $\mathrm{Y}=$ an electronegative fragment) rare-gas containing molecules in low-temperature matrices. It should be emphasized that these molecules are not van der Waals complexes but truly chemically bound species with very characteristic vibrational spectra. The $\mathrm{HKrY}$ and $\mathrm{HXeY}$ molecules are prepared from a suitable hydrogen-containing precursor (HY), which is photodecomposed producing a hydrogen atom and an electronegative fragment (Y). After preparation of the neutral photoproducts, hydrogen atoms are mobilized thermally. The neutral $\mathrm{HKrY}$ and $\mathrm{HXeY}$ molecules are then formed in a concerted reaction $\mathrm{H}+\mathrm{Kr} / \mathrm{Xe}+\mathrm{Y} \rightarrow$ $\rightarrow \mathrm{HXeY} / \mathrm{HKrY}$. Quantum chemical calculations are combined with the experimental results to aid the interpretation and understanding of the structure, spectral characteristics, energetics and bonding of these new molecules. The formation of the $\mathrm{HKrY}$ and $\mathrm{HXeY}$ molecules involves motion of hydrogen atoms and the extent of photo and thermally activated chemical processes highlights the basic concept of fragment mobilization in the solid rare gas lattice. Studies of the formation of HXY molecules at various precursor concentrations and at different extents of photodissociation indicate strongly that the primary photolysis of HY mole-
HXY linear molecules

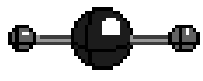

$\mathrm{HXeH}$

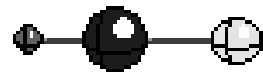

$\mathrm{HXeCl}, \mathrm{HXeBr}, \mathrm{HXel}$, $\mathrm{HXeCN}, \mathrm{HXeNC}$, $\mathrm{HKrCl}, \mathrm{HKrCN}$

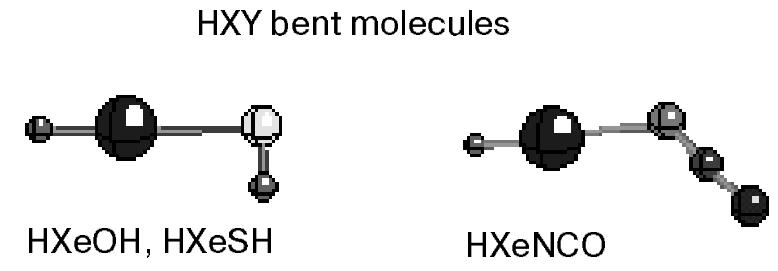

Fig. 1. The known neutral $\mathrm{HKrY}$ and $\mathrm{HXeY}$ molecules.

cules is a very local event. We shall show that the analysis involving the novel compounds can shine light to the solid-state dynamics regarding particularly the mobility of $\mathrm{H}$ atoms. This review is essentially based on experimental and computational research on the reactivity of rare gases carried mainly out at the Laboratory of Physical Chemistry, University of Helsinki during 1995-1999 [56-69], and all the experimentally observed molecules included in this review are shown in Fig. 1.

\section{Computer experiments on $\mathrm{HXeY}$ and $\mathrm{HKrY}$ molecules}

All the HXY ( $\mathrm{X}=\mathrm{Xe}$ or $\mathrm{Kr}$ ) molecules have been prepared in solid rare gases and there does not exist experimental data on their geometries and charge distributions. From the computational point of view the rare-gas containing molecules are challenging. The large number of electrons prohibit quite fast the applicability of extensive quantum chemical methods by increasing the computational task beyond the current computer capabilities. As a useful approach, effective core potentials (ECPs) are used, which reduces the number of electrons taken into account in the calculations. Many possible ECPs are available and usually 8 or 18 electrons are included in the valence shell, and the core is substituted by an effective potential resembling the behaviour of the inner electrons. This approach has been taken in all the studies of $\mathrm{HXeY}$ and $\mathrm{HKrY}$ molecules discussed below, and computational data of the experimentally observed $\mathrm{HXeY}$ and $\mathrm{HKrY}$ molecules is collected in Table 1. 
Table 1

Computational properties of different $\mathrm{HXeY}$ and HKrY compounds at the MP2 level a)

\begin{tabular}{|c|c|c|c|c|c|c|c|c|c|}
\hline \multirow{2}{*}{ Compound } & $r(\mathrm{X}-\mathrm{H})$ & $r(\mathrm{X}-\mathrm{Y})$ & $r(X-Z)$ & \multirow{2}{*}{$q(\mathrm{H})$} & \multirow{2}{*}{$q(\mathrm{X})$} & \multirow{2}{*}{$q(\mathrm{Y})$} & \multirow{2}{*}{$q(\mathrm{Z})$} & \multirow{2}{*}{$\begin{array}{c}\text { Dipole } \\
\text { moment, D }\end{array}$} & \multirow{2}{*}{$\begin{array}{c}\text { EA (Y), } \\
\mathrm{eV}^{\mathrm{e})}\end{array}$} \\
\hline & \multicolumn{3}{|c|}{$\AA$} & & & & & & \\
\hline $\mathrm{HXeH}$ & 1.861 & & & -0.344 & 0.688 & & & 0.0 & 0.754 \\
\hline $\mathrm{HXeSH}^{\mathrm{b})}$ & 1.774 & 2.729 & 1.334 & -0.226 & 0.671 & -0.435 & -0.009 & 4.5 & 2.314 \\
\hline HXeI & 1.747 & 3.095 & & -0.178 & 0.645 & -0.467 & & 6.4 & 3.059 \\
\hline $\mathrm{HXeOH}^{c)}$ & 1.718 & 2.208 & 0.962 & -0.237 & 0.818 & -0.814 & 0.232 & 4.1 & 1.828 \\
\hline $\mathrm{HXeCN}$ & 1.707 & 2.392 & 1.178 & -0.203 & 0.847 & -0.401 & -0.242 & 7.4 & 3.821 \\
\hline $\mathrm{HXeBr}$ & 1.694 & 2.837 & & -0.156 & 0.802 & -0.647 & & 7.3 & 3.364 \\
\hline $\mathrm{HXeCl}$ & 1.685 & 2.663 & & -0.165 & 0.816 & -0.651 & & 7.2 & 3.613 \\
\hline $\mathrm{HXeNCO}^{\mathrm{d}}$ ) & 1.675 & 2.326 & $\mathrm{~N}-\mathrm{C} 1.215$ & -0.169 & 0.863 & -0.566 & C 0.263 & 7.8 & \\
\hline & & & $\mathrm{C}-\mathrm{O} 1.193$ & & & & $\mathrm{O}-0.391$ & & \\
\hline HXeNC & 1.659 & 2.342 & 1.187 & -0.161 & 0.880 & -0.424 & -0.295 & 9.3 & 3.821 \\
\hline $\mathrm{HKrCN}$ & 1.466 & 2.349 & 1.177 & -0.206 & 0.886 & -0.488 & -0.193 & 9.2 & 3.821 \\
\hline $\mathrm{HKrCl}$ & 1.435 & 2.666 & & -0.178 & 0.887 & -0.709 & & 9.4 & 3.613 \\
\hline
\end{tabular}

a) For Xe and Kr 18-VE ECP and for I 17-VE ECP were used, while all other atoms are described by $6-311++\mathrm{G}(2 d, 2 p)$ basis set.

b) The calculated $\mathrm{Xe}-\mathrm{S}-\mathrm{H}$ angle is $91^{\circ}$. c) The calculated angles are $\mathrm{H}-\mathrm{Xe}-\mathrm{O} 177^{\circ}$ and $\mathrm{Xe}-\mathrm{O}-\mathrm{H} 109^{\circ}$. d) The calculated angles $\mathrm{H}-\mathrm{Xe}-\mathrm{N}, \mathrm{Xe}-\mathrm{N}-\mathrm{C}$ and $\mathrm{N}-\mathrm{C}-\mathrm{O}$ are $178^{\circ}, 125^{\circ}$, and $178^{\circ}$, respectively. ${ }^{\mathrm{e})}$ Electron affinity, from Handbook of Chemistry and Physics, CRC Press, Boca Raton, 72nd ed. (1991).

Calculated structures and energetics. The first computational studies of $\mathrm{HXeY}$ and $\mathrm{HKrY}$ molecules employed second-order perturbation theory and small basis sets (MP2/LANL1DZ) [53,54]. These calculations are very economic and fast, and at the equilibrium structures they are surprisingly adequate. Up to now our experience of these calculations on the $\mathrm{HXeY}$ and $\mathrm{HKrY}$ molecules shows that they are able to predict the existence of the molecule. This fact is evidenced for example with halogen containing HKrY molecules. The calculations predict that $\mathrm{HKrCl}$ should exist but $\mathrm{HKrBr}$ and $\mathrm{HKrI}$ are not stable. Indeed, this corresponds to experimental observations and only $\mathrm{HKrCl}$ has been isolated in low-temperature matrices [56], but not $\mathrm{HKrBr}$ or HKrI despite extensive attempts. These low-level MP2/LANL1DZ calculations give reasonable bond distances and vibrational frequencies. On the other hand, they predict the HXY molecules to be higher in energy than the neutral atomic dissociation limit. For higher level calculations this is reversed as pointed out by Runeberg and cowork- ers based on their high-level ab initio calculations on $\mathrm{HXeH}[70,71]$. This work is the best and most extensive computation on $\mathrm{HXeH}$, and the authors studied its structural and vibrational properties as well as the energetics at various computational methods from the perturbation theory (MPn) to the state-of-art coupled cluster (CCSD(T)) and multireference configuration interaction (MR-CI) calculations. The study showed that increasing the level of correlation requires also a larger and flexible basis set to achieve chemically reliable results for $\mathrm{HXeH}$. For this molecule, practical methods like MP2 with a standard basis set including multiple polarization and diffuse functions predict a $\mathrm{Xe}-\mathrm{H}$ bond distance of ca. $1.86 \AA$. The most extensive $\operatorname{CCSD}(\mathrm{T})$ calculations by Runeberg et al. [70,71] estimate the $\mathrm{Xe}-\mathrm{H}$ bond in $\mathrm{HXeH}$ to be ca. $1.95 \AA$. It must be noted here that this value is much shorter than the $\mathrm{Xe}-\mathrm{H}$ van der Waals minimum being $3.8 \AA$ [72].

For all known Xe-containing hydrides the MP2 calculations estimate a $\mathrm{Xe}-\mathrm{H}$ bond between 1.66 
and $1.86 \AA$, the longest $\mathrm{Xe}-\mathrm{H}$ bond being found for $\mathrm{HXeH}$. It can be noted that the calculated parameters follow a general trend. The $\mathrm{H}-\mathrm{Xe}$ bond length decreases with the increasing partial positive charge on xenon. The positive charge residing on xenon is largest $(+0.88)$ for the HXeNC molecule corresponding to the shortest $\mathrm{Xe}-\mathrm{H}$ bond length $(1.659 \AA$ ). For deeper bound HXeY molecules the contribution of $(\mathrm{HXe})^{+}$increases, and the $\mathrm{HX}$ bond length approaches the value of the $\mathrm{XeH}^{+}$cation, for which computations at the same level predict a bond distance of $1.596 \AA$. The reason for this is the larger ionic contribution $(\mathrm{HXe})^{+} \mathrm{Y}^{-}$in the molecule, and this is discussed in more details below. Similarly for the $\mathrm{Kr}$ compounds the increasing charge separation approaches $\mathrm{KrH}^{+}$for which the calculated bond distance is $1.382 \AA$. It is also worth noting that all these molecules have very large dipole moments due to the extensive charge separation.

The HXY molecules observed experimentally up to now are shown in Fig. 1. HXeH is the smallest and simplest of the family of rare gas hydrides but $\mathrm{HKrH}$ does not exist neither computationally nor experimentally. One of the hydrogens in these species can be substituted with an electronegative fragment to form a linear HXY molecule, where $\mathrm{Y}$ is halogen or a pseudohalogen like $\mathrm{CN}$. A second group of rare-gas containing hydrides is obtained from bent hydrogen containing precursors, and the rare gas atom is inserted into the $\mathrm{H}-\mathrm{Y}$ bond. Such molecules characterized so far are: $\mathrm{HXeOH}$, $\mathrm{HXeSH}$ and HXeNCO. The HXeSH molecule is the first example of a $\mathrm{Xe}-\mathrm{S}$ bond [60] with a $\mathrm{Xe}-\mathrm{S}-\mathrm{H}$ angle of ca. $91^{\circ}$, which is very similar to the angle of $\mathrm{H}_{2} \mathrm{~S}$. Moreover, the calculated $\mathrm{S}-\mathrm{H}$ bond distance of $1.334 \AA$ is very close to the experimental $\mathrm{S}-\mathrm{H}$ bond in $\mathrm{H}_{2} \mathrm{~S}$ being $1.336 \AA$ [73]. Similarly the $\mathrm{HXeOH}$ and $\mathrm{HXeNCO}$ molecules follow closely the structure of their precursors, i.e., water and HNCO. It appears that the rare gas atom inserted into a covalent $\mathrm{H}-\mathrm{Y}$ bond has a negligible effect on the rest of the molecule. This observation opens up interesting possibilities that can be in the first place tested by computational methods. The success with $\mathrm{Xe}$ insertion into the $\mathrm{O}-\mathrm{H}$ bond of water prompted us also to test this idea on larger systems. Computations on formic acid indicate that the $\mathrm{HCOOXeH}$ molecule is stable, and the HCOO-group is only little perturbed from its structure in the $\mathrm{HCOOH}$ monomer [74]. This idea can be extended to other carboxylic acids and amino acids which all behave similarly to formic acid. The largest molecule tested was aspartic acid $\left(\mathrm{HOOCCH}_{2} \mathrm{CHNH}_{2} \mathrm{COOH}\right)$, where the most prominent insertion of Xe was noted into the side chain of the molecule.This result suggests that in principle Xe can bind metastably to amino acids, which are building blocks for proteins. In this respect it is important to note that anesthetic substances were suggested to bind directly to proteins, but yet no definitive evidence of the location of the binding sites exists [75]. Since Xe is known to have an anesthetic effect, the insertion of Xe into a covalent $\mathrm{O}-\mathrm{H}$ bond might have an impact on understanding its anesthetic mechanism.

It should be noted that the HXeY and HKrY molecules are computationally practically linear with respect to the $\mathrm{H}-\mathrm{Xe}-\mathrm{Y}$ bond. For $\mathrm{HXeOH}$ the deviation from linearity is about $3^{\circ}$ and for the carboxylic and amino acids deviations up to $5^{\circ}$ have been reported [74]. For the nitrogen bound Xe compound HXeNCO a few degrees tilt in the $\mathrm{H}-\mathrm{Xe}-\mathrm{N}$ bond is found [68]. Previously also for $\mathrm{FXeOSO}_{2} \mathrm{~F}$ the $\mathrm{F}-\mathrm{Xe}-\mathrm{O}$ angle was reported to be $177.5^{\circ}$ [76], bearing some similarity to the $\mathrm{H}-\mathrm{Xe}-\mathrm{O}$ and $\mathrm{H}-\mathrm{Xe}-\mathrm{N}$ groups in the $\mathrm{HXeY}$ molecules. In principle, a simple explanation for this can be found from the three-center four-electron model applied for FXeF [17] and HXeH [70,71]. The highest occupied $\left(\sigma_{q}\right)$ orbital is centered around the terminal $\mathrm{H}$ and $\mathrm{F}$ atoms in $\mathrm{HXeH}$ and $\mathrm{FXeF}$, respectively. This molecular orbital is nonbonding and occupies two electrons. In $\mathrm{HXeH}$, the lowest orbital $\left(\sigma_{q}\right)$ is formed from the $5 p$ orbital of xenon and the $s$ orbitals of the hydrogens. This molecular orbital possesses additional two electrons and is responsible for the covalent bonding. A similar simple linear model should be valid also for other HXY molecules by replacing the other $s$ orbitals by the proper orbital of the $\mathrm{Y}$ fragment. The tilt in the linear bond indicates small external perturbations in the bonding induced by the rest of the molecule.

A model of bonding. Even though the equilibrium structure of the HXeY and HKrY molecules are qualitatively reproduced also with the modest computational approaches compared to the state-of-art approaches, the energetics of the rare-gas containing molecules is more challenging. The origin of the bonding can be understood on the basis of a model where both neutral (HXY) and ionic $\left(\mathrm{HX}^{+} \mathrm{Y}^{-}\right)$bonds contribute. The idea of the ion pair was originally applied on $\mathrm{HXe}^{+} \mathrm{Cl}^{-}$by Last and George based on semiempirical DIIS calculations [77]. It is informative to discuss the main factors affecting the stability of the HXY molecules. In principle the HXY molecules have strong ionic nature at the equilibrium structure, which is evident from the partial charges in Table 1. This equilibrium structure corresponds to an ion pair disso- 
ciation limit $\mathrm{HX}^{+}+\mathrm{Y}^{-}$. However, when the $\mathrm{HXY}$ molecule is stretched along the molecular axis the ionic adiabatic potential surface is crossed by a repulsive surface corresponding to the neutral fragments $\mathrm{H}+\mathrm{X}+\mathrm{Y}$. The dissociation limit of the HXY molecules corresponds to the neutral fragments due to the avoided crossing between the neutral and ionic potential surfaces. Therefore, the ionization potential (IP) of $\mathrm{X}$, electron affinity (EA) of $\mathrm{Y}$ and the dissociation energy $\left(D_{e}\right)$ of $\mathrm{XH}^{+}$determine the energetics between the neutral and ionic limits. A low ionization potential of $\mathrm{X}$ and a large electron affinity of $\mathrm{Y}$ are favourable to the formation of $\mathrm{HXY}$. The $D_{e}$ values of $\mathrm{XeH}^{+}$and $\mathrm{KrH}^{+}$are about 4.05 and $4.8 \mathrm{eV}$, respectively [78-81]. The closer the ionic surface lies to the neutral surface, the larger interaction between the two surfaces is expected and the further the avoided crossing is from the HXY minimum. Altogether, there is a rather subtle balance between the different factors affecting the energetics of HXY compounds and their properties depend strongly on Y. One factor is the electron affinity of the Y-fragment (shown in Table 1) and also the effective size of $\mathrm{Y}$. Small $\mathrm{Y}^{-}$could be thought intuitively to stabilize HXY more than a larger one because it can approach closer to the $\mathrm{HX}^{+}$fragment hence producing a larger Coulombic stabilization. This consideration indicates that the lighter rare gases, especially argon, could form similar HArY molecules. However, the ionization potential of $\mathrm{Ar}$ is larger $(15.759 \mathrm{eV})$ than that of $\mathrm{Kr}$ and $\mathrm{Xe}$, and $\mathrm{ArH}^{+}$is less stable $(3.87 \mathrm{eV})$ than $\mathrm{KrH}^{+}$and $\mathrm{XeH}^{+}$[82]. Nevertheless, based on the simple arguments discussed above argon could combine with an extremely electronegative fragment to form a new HArY molecule. Indeed, computationally both $\mathrm{HArCl}$ and $\mathrm{HArF}$ have been characterized [56]. $\operatorname{CCSD}(\mathrm{T}) / 6-31 \mathrm{G}(d, p)$ calculations predict HArF to be the more strongly bound of these two molecules with a binding energy of $0.2 \mathrm{eV}$ [56].

In terms of resonance structures, HXY should be described as a resonance hybrid between several possible structures, the most important being $\mathrm{HX}^{+} \mathrm{Y}^{-}$. The other important structures are neutral $\mathrm{H}-\mathrm{X}-\mathrm{Y}$ and ionic $\mathrm{H}^{-} \mathrm{X}^{+} \mathrm{Y}$. The ionic structures tend to stabilize the compound and the neutral structure destabilizes it. Recently, the bonding nature of HXY molecules has been studied by topological analysis of the Electron Localization Function (ELF), in which three different resonance structures were considered: $\mathrm{H}^{+} \mathrm{XY}^{-}, \mathrm{HX}^{+} \mathrm{Y}^{-}$and $\mathrm{HX}^{-} \mathrm{Y}^{+}$ [83]. For $\mathrm{HXeCl}$ and $\mathrm{HKrCl}$ the second structure has the largest weight being about $60 \%$. For the first structure the approximate weight is about $20 \%$, and the remaining $20 \%$ resides on the structure with the positive charge localized on the halogen. Therefore, it was concluded that the positive charge is mainly localized on the rare gas atom, and that the $\mathrm{H}-\mathrm{X}$ bond was mostly covalent in nature. It was concluded about the interaction between the rare gas atom and the halogen that this binding is mostly of a so called unshared-electron type, i.e., the interaction is mainly ionic but with a nonnegligible fraction of a covalent character. This conclusion is in agreement with the simple model derived above where both neutral and ionic potential surfaces contribute to the HXY molecule.

The $\mathrm{H}-\mathrm{X}$ bond distance reflects directly the fraction of the ionic contribution in the molecule. The computationally strongest HXY molecule among the experimental observed ones is $\mathrm{HXeCN}$, which has a dissociation energy of $1.43 \mathrm{eV}$ [59] with respect to the dissociation limit $\mathrm{H}+\mathrm{Xe}+\mathrm{CN}$. CISD (configuration interaction with single and double excitations) calculations on $\mathrm{HXeCl}$ estimate the binding energy to be $0.9 \mathrm{eV}$, and also the first excited state was found to include a minimum in accordance with the curve crossing. The first excited state was calculated to be bound by $2.0 \mathrm{eV}$ and lie almost $5 \mathrm{eV}$ above the ground state at the $\mathrm{X}^{1} \Sigma^{+}$equilibrium structure [84]. In general, computationally the ground state HXY molecules are bound by $0.4-1.4 \mathrm{eV}$.

Vibrational properties. The agreement of the calculated and experimental vibrational frequencies reflect the adequacy of the potential energy surface by a given theoretical approach. As noted above, the equilibrium structures are reasonably well reproduced already at modest computational levels, and therefore the vibrational frequencies are also qualitatively correct. However, the HXY molecules are relatively weakly bound and the potential energy surface near the dissociation limit can not be described accurately without extensive basis sets and electron correlation. For HXeH the MP2 calculation gives the following frequencies: symmetric stretch at $1559 \mathrm{~cm}^{-1}$, antisymmetric stretch at $1385 \mathrm{~cm}^{-1}$ and bending at $876 \mathrm{~cm}^{-1}$. Increasing the electron correlation to $\operatorname{CCSD}(\mathrm{T})$ decreases both the symmetric and the antisymmetric stretches to 1279 and $1216 \mathrm{~cm}^{-1}$, respectively [70,71]. Also, the $\operatorname{CCSD}(\mathrm{T})$ calculations predict the bending mode at $773 \mathrm{~cm}^{-1}$. Recently we studied the effect of anharmonicity for $\mathrm{HXeH}$ at the MP2 level, and found that both the antisymmetric stretch and the bending modes are much more harmonic than the symmetric stretch [85]. These results are collected in Table 2 and compared with the harmonic MP2 and $\operatorname{CCSD}(\mathrm{T})$ results. The symmetric stretch, which 
Comparison of calculated and measured vibrational frequencies of some $\mathrm{HXeY}$ compounds. The numbers in the parentheses are the IR intensities ${ }^{\mathrm{a})}\left(\right.$ in $\left.\mathrm{km} \cdot \mathrm{mol}^{-1}\right)$

\begin{tabular}{|c|c|c|c|c|c|}
\hline Compound & $v(\mathrm{Xe}-\mathrm{H})$ & $2 v(\mathrm{Xe}-\mathrm{H})$ & $\delta(\mathrm{H}-\mathrm{Xe}-\mathrm{Y})$ & $2 \delta(\mathrm{H}-\mathrm{Xe}-\mathrm{Y})$ & $v\left(\mathrm{Xe}^{-} \mathrm{Y}\right)$ \\
\hline $\mathrm{HXeH}$ & & & & & \\
\hline MP2 harm. & $1385(2503)$ & & $876(69)$ & & $1559(0)$ \\
\hline $\operatorname{CCSD}(\mathrm{T})$ harm. & 1279 & & 773 & $1666(0)$ & 1216 \\
\hline MP2 anharm. & 1337 (4594) & $2648(0)$ & $839(69)$ & & $1469(0)$ \\
\hline Experiment & 1166,1181 & & 701 & & $840^{b)}$ \\
\hline $\mathrm{HXeCl}$ & & & & & \\
\hline MP2 harm. & $1740(2058)$ & & $595(4)$ & $1143(0)$ & $267(46)$ \\
\hline MP2 anharm. & $1642(1288)$ & $3194(20)$ & $577(2)$ & $1140(0)$ & $260(2)$ \\
\hline Experiment & 1648 & & & & \\
\hline $\mathrm{HXeBr}$ & & & & & \\
\hline MP2 harm. & $1679(4102)$ & & $526(1)$ & & $182(29)$ \\
\hline MP2 anharm. & $1544(1445)$ & $2967(15)$ & $506(2)$ & $997(33)$ & $180(48)$ \\
\hline Experiment & 1504 & 2869 & 489 & 965 & \\
\hline HXeI & & & & & \\
\hline MP2 harm. & $1514(5423)$ & & $500(1)$ & & $143(18)$ \\
\hline MP2 anharm. & 1359 (2429) & $2585(51)$ & 477 (1) & $937(44)$ & $142(38)$ \\
\hline Experiment & 1193 & 2190 & 450 & 886,896 & $129^{\mathrm{c})}$ \\
\hline $\mathrm{HXeOH}$ & & & & & \\
\hline MP2 harm. & $1823(1456)$ & & $653(7)^{d)}$ & & $437(126)^{e)}$ \\
\hline $\operatorname{CCSD}(\mathrm{T})$ harm. & 1678 & & $629^{\text {d) }}$ & & $419^{\mathrm{e})}$ \\
\hline $\begin{array}{l}\text { MP2 anharm. } \\
\text { Experiment }\end{array}$ & $\begin{array}{c}1713(1043) \\
1578\end{array}$ & 3342 ( 12) & $\left.627(5)^{d}\right)$ & $1242(4)$ & $425(269)^{e)}$ \\
\hline
\end{tabular}

a) Calculated using dipole moments obtained from SCF wavefunctions. ${ }^{b)}$ Calculated from the $v_{1}+v_{3}$ combination band observed at $2003 \mathrm{~cm}^{-1}$. c) Calculated from the $v_{1}+v_{3}$ combination band observed at $1322 \mathrm{~cm}^{-1}$. d) HXeO out-of-plane bend. ${ }^{1}$ ) $\mathrm{Xe}-\mathrm{OH}$ stretch.

corresponds to the lowest energy path for dissociation of the molecules, is predicted to decrease by about $100 \mathrm{~cm}^{-1}$ from its harmonic value.

The anharmonic vibrational calculations are based on the ab initio calculated points on the potential energy surface, which allows us to estimate the wavenumbers of the combinations overtones. For example, an experimentally observed band at $2003 \mathrm{~cm}^{-1}$ belongs to $\mathrm{HXeH}$, but no conclusive assignments for this mode could be given. The anharmonic MP2 calculations predict the combination band of the symmetric and antisymmetric stretchings to have significant intensity, and we can assign the $2003 \mathrm{~cm}^{-1}$ band accordingly. This gives us an indirect measure of the IR-inactive symmetric stretch, which should be at ca. $840 \mathrm{~cm}^{-1}$. The derived wavenumber is much lower than predicted by any computational methods using harmonic approach to calculate the vibrational frequencies.
The $\mathrm{X}-\mathrm{H}$ stretching motion is an essential part of the vibrational calculation of the HXY molecules. For more strongly bound HXY molecules the MP2 vibrational calculations become better but $\mathrm{HXeH}$ (as well as $\mathrm{HXeSH}$ ) represents a borderline case and require more sophisticated computational approaches. In the course of our work, we have found that even the moderate MP2 calculations give reasonable qualitative results not only for the structures, charge separation and vibrational frequencies but also for the large intensities of the $\mathrm{X}-\mathrm{H}$ stretching absorptions. The calculated intensities for the $\mathrm{Xe}-\mathrm{H}$ stretch in various molecules are shown also in Table 2. For the strongly bound molecules like $\mathrm{HXeCl}$ and $\mathrm{HXeBr}$, the MP2 calculations are good enough to reproduce the correct molecular properties and PES characteristics. Even though the computational vibrational frequencies are generally overestimated the systematic trend among the pre- 


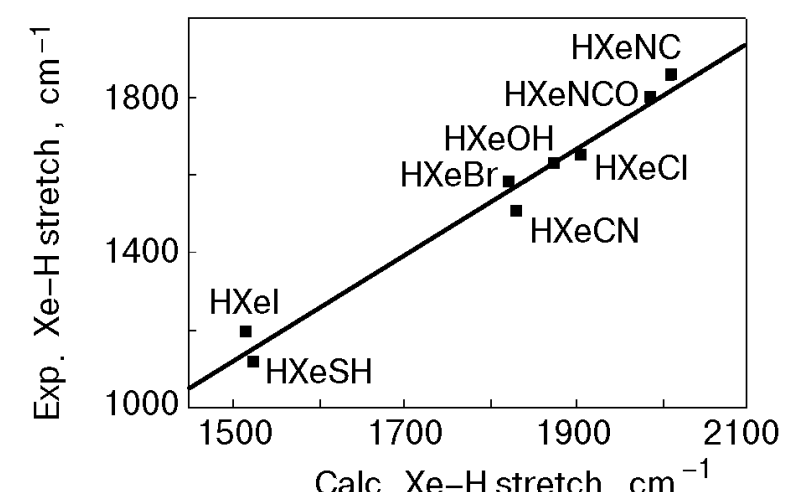

Fig. 2. Comparison of calculated (MP2) and experimental $\mathrm{Xe}-\mathrm{H}$ stretching values for $\mathrm{HXY}$ molecules.

sent HXY molecules is correctly predicted. When a HXY molecule is strongly bound, the $\mathrm{Xe}-\mathrm{H}$ bond distance is shorter and this is reflected as a blueshift of the $\mathrm{X}-\mathrm{H}$ stretching vibration. This is in accord with the experimental $\mathrm{Xe}-\mathrm{H}$ wavenumbers which shift to higher values from the weakest bound $\mathrm{HXeSH}$ to the strongest bound HXeNC, as shown in Fig. 2, where the experimentally observed $\mathrm{Xe}-\mathrm{H}$ stretching wavenumbers are plotted against the calculated harmonic values. For comparison, the $\mathrm{XeH}^{+}$vibrational frequency in the gas phase has been reported at $2270 \mathrm{~cm}^{-1}$ [78].

\section{Experimental results}

Formation of $\mathrm{HKrY}$ and $\mathrm{HXeY}$ molecules. The starting point for solid-state synthesis of the HXY molecules is to choose a hydrogen-containing precursor like $\mathrm{H}_{2} \mathrm{O}, \mathrm{H}_{2} \mathrm{~S}$, hydrogen halides, $\mathrm{HNCO}$, etc. The precursor molecule (HY) is diluted with excess of krypton or xenon, and the mixture is trapped on a cold surface of an IR transparent window. It is important that the precursor is as monomeric as possible, since precursor aggregation complicates the photochemistry, as shown, for example, in the case of hydrogen halides [86]. In order to promote the isolated precursor to a dissociative state, various light sources can be used. For hydrogen halides simple UV lamps are suitable since the dissociation energies of these molecules are around $4 \mathrm{eV}$ [87]. Additionally in the preparation of HXY molecules, excimer lasers (248, 193, and $157 \mathrm{~nm}$ ) and tunable (down to $225 \mathrm{~nm}$ ) radiation of an optical parametric oscillator have been used. The main objective of the photodecomposition process is to separate the $\mathrm{H}$ and $\mathrm{Y}$ fragment of the $\mathrm{HY}$ precursor. The extent of the mobility of the fragments during the primary photolysis, especially of the hot $\mathrm{H}$ atoms, will be addressed below.
Upon photolysis, neutral fragments $\mathrm{H}$ and $\mathrm{Y}$ are localized in a rare gas matrix. For example, in the cases of $\mathrm{HI}$ and $\mathrm{HBr}$ the presence of $\mathrm{I}$ and $\mathrm{Br}$ atoms is clearly evidenced by their spin-orbit $\left({ }^{2} P_{1 / 2} \leftarrow{ }^{2} P_{3 / 2}\right)$ absorptions at ca. 7600 and $3600 \mathrm{~cm}^{-1}$, respectively [61]. Both the $\mathrm{H}$ atoms and $\mathrm{Y}$ fragments are stable below the mobilization temperature of hydrogen atoms $(30-50 \mathrm{~K})$. In very dilute matrices $(\mathrm{M} / \mathrm{A}$ ratio $>1000)$, it is possible to convert a major part of the precursor to $\mathrm{H}$ atoms and neutral $\mathrm{Y}$ fragments. In more concentrated matrices, other processes like clusterization and photoinduced reactions of hydrogen atoms produce more complicated products as well as hydrogen molecules $[61,88]$. The second step in the solidstate synthesis of HXY molecules is annealing of the photolyzed matrix to the point where the $\mathrm{H}$ atoms start to diffuse. Several separate experiments have shown that the diffusion occurs at ca. 30 and $40 \mathrm{~K}$ in solid $\mathrm{Kr}$ and $\mathrm{Xe}$ [59,88-93]. The diffusing $\mathrm{H}$ atoms find eventually a rare gas atom which has a fragment $Y$ as a near neighbor, and the three fragments $\mathrm{H}, \mathrm{Y}$, and $\mathrm{X}$ react forming the $\mathrm{HXY}$ molecule. Reaction of two hydrogen atoms with a $\mathrm{Xe}$ atom between them produce $\mathrm{HXeH}$. In the case of krypton, this last reaction has not been observed to occur, and also computationally $\mathrm{HKrH}$ molecule is unstable. Most importantly, in solid Xe the $\mathrm{HXeY}$ and $\mathrm{HXeH}$ molecules seem to be the major trapping sites for $\mathrm{H}$ atoms and $\mathrm{Y}$ fragments in solid rare gases after mobilization of hydrogen atoms [65].

A valuable observation was made concerning the formation of the HXeNCO molecule in HNCO photolysis in solid Xe [68]. The rare gas molecule was observed to form not only in the annealing but also directly in the photolysis of HNCO. The kinetics of HXeNCO was followed during $193 \mathrm{~nm}$ photolysis, and the HXeNCO molecule rises rapidly, reaches a maximum and decreases eventually completely due to its own photodecomposition. The experiment was performed photolyzing HNCO using different wavelengths $(225,240,250,266 \mathrm{~nm})$ but the formation of HXeNCO was observed to occur only at $193 \mathrm{~nm}$ irradiation. The maximum concentration of HXeNCO produced during photolysis was estimated to be about $0.4 \%$ from the initial concentration of the precursor HNCO. There are different alternatives for the mechanism of formation of HXeNCO: HXeNCO can be formed directly from $\mathrm{HNCO} / \mathrm{Xe}$ in a photoisomerization process, or it can be formed from a hydrogen atom loosing its kinetic energy in the immediate vicinity of the $\mathrm{NCO}$ fragment. Nevertheless, once formed the subsequent 
photodecomposition of $\mathrm{HXeNCO}$ provides much Table 3 more kinetic energy to the $\mathrm{H}$ atom than the direct dissociation of the HNCO precursor at the same irradiation wavelength. Finally, it should be noted that HXeNCO can be decomposed by $405 \mathrm{~nm}$ irradiation and it produces $\mathrm{HNCO}$ and $\mathrm{H}+\mathrm{NCO}$ with a branching ratio of $70 \% / 30 \%$ [68].

In general, the HXY molecules are easily detected by IR spectroscopy due to the extremely intensive $\mathrm{X}-\mathrm{H}$ stretching absorptions [56-60,62$64,68]$, and the position of the stretching band is very characteristic for each $\mathrm{Y}$. In addition to the $\mathrm{Xe}-\mathrm{H}$ absorption bands, other bands like combinations, overtones and fundamental bands characteristic of the Y-residue in the HXY molecules have been observed, and they are collected in Tables 2 and 3 including also frequencies for the deuterated species. A striking example of the sensitivity of the $v(\mathrm{Xe}-\mathrm{H})$ absorption on the properties of the $\mathrm{Y}$ fragment is found by comparing the two isomers of $\mathrm{HXeCN}$. The lowest energy isomer $\mathrm{HXeCN}$ the $v(\mathrm{Xe}-\mathrm{H})$ absorption is at $1624 \mathrm{~cm}^{-1}$ and it shifts by $+227 \mathrm{~cm}^{-1}$ to $1851 \mathrm{~cm}^{-1}$ for the higher energy species $\mathrm{HXeNC}$ [59]. In fact, this also measures the anisotropy of the $\mathrm{CN}$ fragment.

Several vibrational overtones and combinations have been reported for the HXY molecules (see Table 2). For HXeI and $\mathrm{HXeBr}$ both the bending and the $\mathrm{Xe}-\mathrm{H}$ stretching overtones show measurable intensities arising from anharmonic effects. The most striking effect is the enhanced intensity of the bending overtones compared with the fundamental bands for $\mathrm{HXeBr}$ and HXeI. For $\mathrm{HXeCl}$, the bending overtone is predicted by anharmonic MP2 calculations to be of small intensity, and indeed, this vibration has not been observed experimentally. For the $\mathrm{Xe}-\mathrm{H}$ stretching vibrations of $\mathrm{HXeBr}$ and HXeI, the first overtones are computationally rather weak compared with the fundamental modes but they are still intensive enough to be experimentally observed.

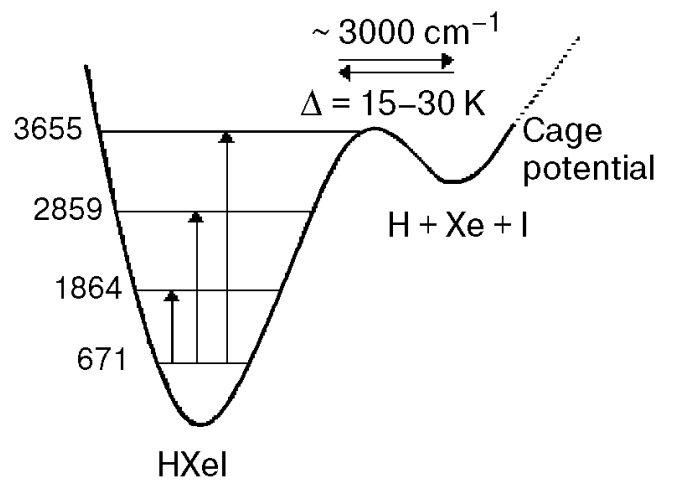

Fig. 3. Photodissociation upon IR irradiation and recombination upon annealing of $\mathrm{HXeI}$.

The observed IR absorptions (in $\mathrm{cm}^{-1}$ ) of different $\mathrm{HXeY}$ and HKrY compounds

\begin{tabular}{|c|c|c|c|c|}
\hline Compound & $\begin{array}{c}v \\
{[\mathrm{X}-\mathrm{H}(\mathrm{D})]}\end{array}$ & $\mid \begin{array}{c}\delta \\
{[\mathrm{H}-\mathrm{X}-\mathrm{Y}]}\end{array}$ & $\begin{array}{c}v \\
{[\mathrm{X}-\mathrm{Y}]}\end{array}$ & $\begin{array}{c}v \\
{[\mathrm{Y}]}\end{array}$ \\
\hline $\mathrm{HXeCl}$ & 1648 & & & \\
\hline $\mathrm{DXeCl}$ & 1198 & & & \\
\hline $\mathrm{HXeBr}$ & 1504 & 489 & & \\
\hline $\mathrm{DXeBr}$ & 1100 & & & \\
\hline $\mathrm{HXeI}$ & 1193 & 450 & $129^{\mathrm{a})}$ & \\
\hline DXeI & 893 & & & \\
\hline $\mathrm{HXeCN}$ & 1624 & & & \\
\hline $\mathrm{DXeCN}$ & 1178 & & & \\
\hline HXeNC & 1851 & & & $2044(\mathrm{vCN})$ \\
\hline DXeNC & 1339 & & & \\
\hline $\mathrm{HXeNCO}$ & 1788 & & & $2148\left(v_{\mathrm{as}} \mathrm{NCO}\right)$ \\
\hline DXeNCO & 1299 & & & $2145\left(v_{\mathrm{as}} \mathrm{NCO}\right)$ \\
\hline $\mathrm{HXeOH}$ & 1578 & & & \\
\hline HXeOD & 1572 & & & \\
\hline $\mathrm{DXeOH}$ & 1149 & & & \\
\hline $\mathrm{DXeOD}$ & 1141 & & & \\
\hline $\mathrm{HXeSH}(\mathrm{D})$ & 1119 & & & \\
\hline $\mathrm{DXeSH}(\mathrm{D})$ & 833 & & & \\
\hline $\mathrm{HXeH}$ & $\begin{array}{c}1166,1181\left(v_{\mathrm{as}}\right) \\
840\left(\mathrm{v}_{\mathrm{sym}}\right)^{\mathrm{b})}\end{array}$ & 701 & & \\
\hline $\mathrm{HXeD}$ & $\begin{array}{r}1093(v \mathrm{Xe}-\mathrm{H}) \\
753(v \mathrm{Xe}-\mathrm{D})\end{array}$ & 621 & & \\
\hline $\mathrm{DXeD}$ & 846,856 & 514 & & \\
\hline $\mathrm{HKrCl}$ & 1476 & 544 & & \\
\hline $\mathrm{DKrCl}$ & 1106 & & & \\
\hline $\mathrm{HKrCN}$ & 1497 & 618 & & \\
\hline $\mathrm{DKrCN}$ & 1109 & & & \\
\hline
\end{tabular}

a) Calculated from the difference between the $v_{1}+v_{3}$ combination band $\left(1322 \mathrm{~cm}^{-1}\right)$ and the antisymmetric stretch $\left(v_{3}\right.$, $1193 \mathrm{~cm}^{-1}$ ). b) Calculated from the difference between the $v_{1}+v_{3}$ combination band $\left(2003 \mathrm{~cm}^{-1}\right)$ and the antisymmetric stretch $\left(v_{3}, 1166 \mathrm{~cm}^{-1}\right)$.

The overtones of HXeI have played an important role in resolving the mechanism of formation of the HXY molecules [58]. The $v(\mathrm{Xe}-\mathrm{H})$ frequency of HXeI is at $1193 \mathrm{~cm}^{-1}, 2 v(\mathrm{Xe}-\mathrm{H})$ is at $2190 \mathrm{~cm}^{-1}$, and around energies $3 \mathrm{v}(\mathrm{Xe}-\mathrm{H})$ close to $3000 \mathrm{~cm}^{-1}$ the molecule decomposes [58]. This is schematically shown in Fig. 3. The HXeI infrared photodissoci- 
ation experiment yields an absorption profile for the $3 v(\mathrm{Xe}-\mathrm{H})$ transition with an onset at $2950 \mathrm{~cm}^{-1}$, which could be considered as an approximate value for the $D_{0}$ dissociation energy of HXeI. After the IR decomposition the molecular form can be restored by annealing at temperatures considerably below those needed for the global mobilization of $\mathrm{H}$ atoms in solid xenon. Therefore, the $3 v(\mathrm{Xe}-\mathrm{H})$ excitation of $\mathrm{HXeI}$ produces atoms in a close contact with each other and $\mathrm{HXeI}$ can be recovered by slight warming or even at the lowest temperatures by tunneling as pictured in Fig. 3. The increase of the spin-orbit absorption of iodine atoms at ca. $7600 \mathrm{~cm}^{-1}$ correlated with the infrared induced decrease of HXeI and vice versa [58]. The low energy of the infrared photons is not sufficient to produce ionic centers in the matrix indicates that the HXY molecules correlate with the neutral atom asymptote. Additional evidence for formation of HXY from neutral atoms is available from Feldman and coworkers [91,92]. These authors combined infrared and ESR-spectroscopic methods to study electron-irradiated xenon matrices containing various hydrocarbons, and they found that the decrease of hydrogen atoms correlated with the growth of $\mathrm{HXeH}$. Adding electron scavengers which enhance ion formation decreased the yield of $\mathrm{HXeH}[91,92]$.

We can also estimate the anharmonicity of the $v(\mathrm{Xe}-\mathrm{H})$ strecth from the experiments and the derived anharmonicity constant $\left(\omega_{e} x_{e}\right)$ is about $100 \mathrm{~cm}^{-1}$ in solid Xe [94]. This value has been used to calculate the energy levels of $v(\mathrm{Xe}-\mathrm{H})$ in HXeI and they are marked accordingly in Fig. 3. The experimentally derived barrier height for the recombination of the neutral fragments to form HXeI is ca. $700 \mathrm{~cm}^{-1}$ [58].

As mentioned above, one of the weakest bound molecules HXeI dissociates already at $3 v(\mathrm{Xe}-\mathrm{H})$ excitation. Besides this, the electronically excited states lead to decomposition of the HXY molecules. All HXY molecules decompose with visible or UV light, and the decomposition onsets vary from near IR to $350 \mathrm{~nm}$. HXeH was found to be the most photostable member of this family, and it is rather long-lived under $400 \mathrm{~nm}$ irradiation. The electronic states involved in the photodecomposition of the HXY molecules are not known yet but there exist a trend in the VIS-UV-stability of these molecules. For example, the onset of photodecomposition of the halogenated xenon hydrides is the following: HXeI dissociates at wavelengths below $\sim 700 \mathrm{~nm}$, $\mathrm{HXeBr}$ below $\sim 450 \mathrm{~nm}$ and the most stable of this series, $\mathrm{HXeCl}$, requires wavelengths below $\sim 350 \mathrm{~nm}$.
Production of $\mathrm{H}$ atoms in photolysis of small hydrides in solid Xe. Experimental preparation of the HXY hydrides is closely connected with the dynamics of $\mathrm{H}$ atoms in rare-gas solids, both during photolysis and annealing. General description of these processes can be found in a recent review by Apkarian and Schwentner [54], and we discuss below only some aspects of solid-state photolysis related to the present consideration. A number of experiments with $\mathrm{HXeY}$ compounds allow us to estimate the absolute amount of $\mathrm{H}$ atoms generated under UV photolysis of an HY precursor in solid Xe. Especially, this consideration concerns light-induced travel distances of «hot» $H$ atoms after photolysis and their losses via the two most evident reactions: $\mathrm{H}+\mathrm{H} \rightarrow \mathrm{H}_{2}$ and $\mathrm{H}+\mathrm{HY} \rightarrow \mathrm{H}_{2}+\mathrm{Y}$. This approach allows us to distinguish the local and global primary photolysis events.

The UV photolysis of $\mathrm{HI}, \mathrm{HCN}$ and $\mathrm{HNCO}$ in $\mathrm{Xe}$ was studied, and concentrations of I atoms, CN or NCO radicals were measured by IR absorption spectroscopy $[58,59,68]$. It was found that annealing of the photolyzed matrices at $40-50 \mathrm{~K}$ decreases the concentration of I atoms, $\mathrm{CN}$ or NCO radicals typically by about $40 \%$, and this decrease was attributed to the formation of $\mathrm{HXeI}, \mathrm{HXeCN}$ and HXeNCO molecules. Furthermore, HXeH molecules were formed in annealing consuming some part of the photo-generated $\mathrm{H}$ atoms. The results clearly indicate that the amount of $\mathrm{H}$ atoms after photolysis is comparable with the amount of the other dissociated part (I, CN, or NCO), and also with the amount of the photolyzed precursors. It follows that loss channels due to extensive mobility of $\mathrm{H}$ atoms do not play a major role during photolysis of $\mathrm{HY}$ precursors in monomeric matrices.

Ternary $\mathrm{HI} / \mathrm{CO} /$ Xe matrix mixtures were prepared in order to estimate the lower limit of the $\mathrm{H}$ atom concentration produced in photolysis by monitoring the decrease of $\mathrm{CO}$ during annealing due to the reaction $\mathrm{H}+\mathrm{CO} \rightarrow \mathrm{HCO}$ [69]. A $\mathrm{HI} / \mathrm{CO} / \mathrm{Xe}=1 / 2 / 2000$ matrix was extensively photolyzed at $310 \mathrm{~nm}$. Upon annealing, the amount of formed HCO corresponded to $\sim 15 \%$ of photolyzed $\mathrm{HI}$, and $\mathrm{HXeI}$ and $\mathrm{HXeH}$ were formed with an efficiency similar to the case of CO-free matrices. During the photolysis, HCO appeared but its amount remained an order of magnitude smaller than the amount measured after annealing. Thus, the proportion of $\mathrm{H}$ atoms consumed to $\mathrm{HCO}$ during the photolysis is about $1 \%$ despite the twicehigher $\mathrm{CO}$ concentration compared to that of HI. This observation indicates the low probability for the distant reaction of the hot $\mathrm{H}$ atom with $\mathrm{CO}$ 


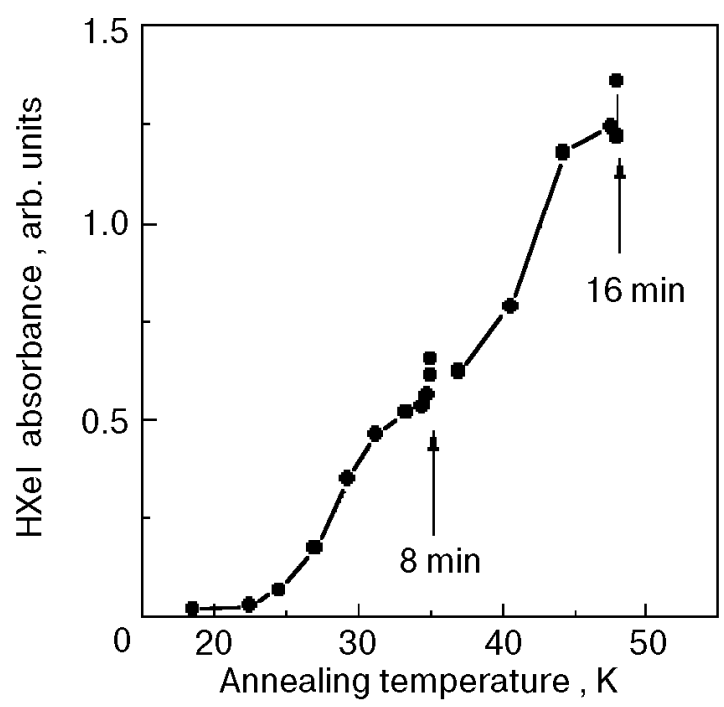

Fig. 4. The formation of $\mathrm{HXeI}$ molecules in annealing. The $\mathrm{HI} / \mathrm{Xe}(1 / 2000)$ matrix was photolyzed at $310 \mathrm{~nm}$. The annealing was performed with the $2 \mathrm{~K} / \mathrm{min}$ rate. At temperatures 35 and $48 \mathrm{~K}$ warming up was stopped for about 8 and $16 \mathrm{~min}$ in order to check the saturation of the reaction.

or/and short-distance travel of $\mathrm{H}$ atoms. It is plausible that a similar inefficiency is also applicable to losses via the reactions $\mathrm{H}+\mathrm{H} \rightarrow \mathrm{H}_{2}$ and $\mathrm{H}+\mathrm{HY} \rightarrow \mathrm{H}_{2}+\mathrm{Y}$.

Thus, it can be concluded that losses of hot $\mathrm{H}$ atoms due to extensive light-induced travel in a low-temperature Xe lattice are quite minor. Moreover, the losses of $\mathrm{H}$ atoms during annealing seem to be essentially due to the formation of Xe-containing molecules. On the other hand, additional losses are evidenced by the gradual decrease of HXeI in multiple cycles of annealing and selective light-induced decomposition of HXeI [69], and formation of $\mathrm{H}_{2}$ molecules is the most probable process. In this respect, the diffusion-limited reactions of $\mathrm{H}$ atoms with $\mathrm{HXeH}$ and $\mathrm{HXeY}$ molecules should be taken into account.

As mentioned earlier, the losses of $\mathrm{H}$ atoms during UV photolysis should be connected with its light-induced travel distance. The experiments with rare-gas containing molecules at various precursor concentrations support only very limited light-induced travel distances under UV photolysis in solid Xe. In this respect, the efficient generation of HXeI in low-temperature annealing ( $30 \mathrm{~K}$ ) of photolyzed $\mathrm{HI}$ / Xe matrices is an important observation [69]. The increase of HXeI during annealing is presented in Fig. 4. Two stages of annealing producing $\mathrm{HXeI}$ can approximately be distinguished around 28 and $40 \mathrm{~K}$, and they should be qualitatively connected with local and global mobility of $\mathrm{H}$ atoms. Indeed, it is well established that the global mobility of $\mathrm{H}$ atoms in solid Xe starts at temperatures above $38 \mathrm{~K}[92,93]$. On the basis of the efficient low-temperature formation of HXeI, we have suggested a quite local distribution of $\mathrm{H}$ atoms in the primary photolysis of $\mathrm{HI}$ in solid Xe [69]. In this model, the locally trapped $\mathrm{H}$ atoms can form HXeI via reacting with the parent I atom in the low-temperature annealing similarly as discussed above for the IR decomposition of HXeI. Furthermore, the local distribution of $\mathrm{H}$ atoms generated in photolysis agrees with the absence of major losses of $\mathrm{H}$ atoms during primary photolysis. This conclusion of minor losses of $\mathrm{H}$ atoms during photolysis should be distinguished from the diffusion-controlled processes during annealing when $\mathrm{H}$ atoms move globally and may quite efficiently form $\mathrm{H}_{2}$ molecules as mentioned earlier.

The experimental model of local photolysis agrees completely with the molecular dynamics simulations of $273 \mathrm{~nm}$ photolysis of $\mathrm{HI}$ in solid Xe $[95,96]$. These computations indicate that the photolysis of $\mathrm{HI}$ is a rather local process and the obtained trajectories lead to trapping of the $\mathrm{H}$ atom in the nearest interstitial sites. Eloranta et al. employed another approach in simulating the distribution of $\mathrm{H}$ atoms under photolysis in different rare-gas matrices [97]. In their study, an $\mathrm{H}$ atom was placed into a substitutional site of a perfect fcc lattice and provided with $2.5 \mathrm{eV}$ of kinetic energy, and most of the resulting trapping position in solid Xe corresponded to the nearest interstitial site.

Experiments with HXeI molecules suggest the existence of hidden secondary processes during photolysis [69]. The proportion of HXeI forming in low-temperature annealing $(<38 \mathrm{~K})$ becomes smaller for longer irradiation times. Most importantly, this proportion decreases further with irradiation time even after complete decomposition of $\mathrm{HI}$, approaching zero for very long irradiation. The $\mathrm{HXeH} / \mathrm{HXeI}$ ratio measured after annealing at $48 \mathrm{~K}$ increases with irradiation time, and it is influenced by the irradiation time after the complete decomposition of $\mathrm{HI}$ as well: it increases in the prolonged photolysis. On the basis of these observations, it was concluded that $\mathrm{H}$ atoms could be driven from the parent cage not only in the preliminary decomposition of HI but also in some secondary processes involving other species. The first hidden process was suggested to be neutralization of $\mathrm{Xe}_{2} \mathrm{H}^{+}$that provides kinetic energy for the $\mathrm{H}$ atom when the Xe atoms relax quickly from the perturbed (bound) configuration to their lattice positions. The mobile electrons providing the neutralization are photodetached from the $\mathrm{Y}^{-}$fragments. 
The other proposed hidden process involves the HXeI potential surface: if an escaping $\mathrm{H}$ atom forms the $\mathrm{HXeI}$ intermediate, it can gain more kinetic energy in photodecomposition of the HXeI molecules. In consonance with the latter hypothesis, HXeNCO was found to form directly in photolysis of $\mathrm{HNCO}$ in solid $\mathrm{Xe}$ as described earlier [68]. In the case of HI, no detectable amount of HXeI is observed in the photolysis of HI, which is most probably due to a very effective photodissociation of HXeI. Up to now, the computer simulations on photolysis of $\mathrm{HI}$ in solid Xe do not include the molecular HXeI potential, and this neglect might be a severe oversimplification of the system suggesting theoretical reinvestigation of the process.

Some controversial conclusions on the dynamics of small hydrides in rare-gas solids can be found in literature. LaBrake et al. suggested a migration distance of $\sim 10 \mathrm{~nm}$ for $\mathrm{H}$ atoms upon $193 \mathrm{~nm}$ photolysis of $\mathrm{HBr}$ in a $\mathrm{Xe}$ matrix, extensive losses of $\mathrm{H}$ atoms via the $\mathrm{H}+\mathrm{HBr} \rightarrow \mathrm{H}_{2}+\mathrm{Br}$ reaction, and a very small amount of $\mathrm{H}$ atoms generated in the photolysis [88]. The conclusions derived in Ref. 88 are based on the deviation of the LIF (laser-induced fluorescence) kinetics of photodissociative fragments from the simplest one-exponential form. Some support for such extensive losses was obtained by Eloranta et al. who reported extremely low amounts of $\mathrm{H}$ atoms in $\mathrm{UV}$ photolysis of $\mathrm{HBr}$ and $\mathrm{HCl}$ in a Xe matrix based on the very weak EPR signals from $\mathrm{H}$ atoms [97]. In a more recent paper of their laboratory [98], a possibility has been presented that the signal from $\mathrm{H}$ atoms trapped only in lattice substitutional sites was measured in Ref. 97.

The origin for the disagreement between the LIF and IR absorption estimates of the photoproduct concentrations in rare-gas matrices can be explained by taking into account the evolution of matrix optical properties during photolysis. The problem with quantitative analysis of photolysis kinetics by using LIF measurements was explicitly demonstrated experimentally. For instance, in the 193-nm photolysis of $\mathrm{HCN} / \mathrm{Kr}$ matrices, the $775-\mathrm{nm}$ emission of $\mathrm{CN}$ clearly saturates faster than its IR absorption does (Fig. 5) and this saturation was explained by self-limitation of the photolysis [63]. Other related examples can be found elsewhere [67]. The observed disproportion evidently breaks the assumption of proportionality between the LIF signal and the product concentration used in Ref. 88, casting strong doubts about the numerical estimates of travel distance and losses of $\mathrm{H}$ atom during $\mathrm{HBr}$ photolysis in Xe.

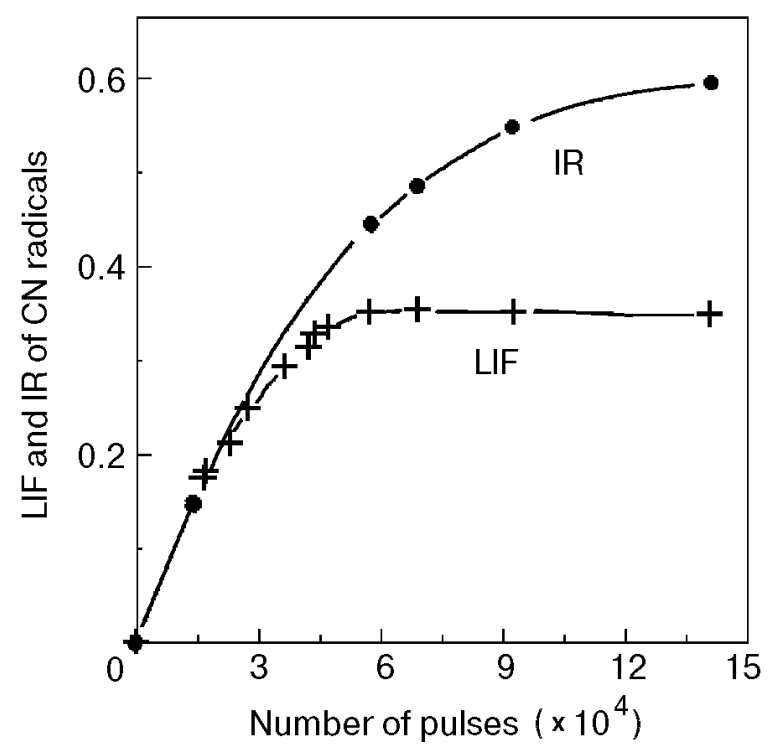

Fig. 5. The LIF and IR absorption kinetics of $\mathrm{CN}$ during $193 \mathrm{~nm}$ photolysis of a $\mathrm{HCN} / \mathrm{Kr}$ matrix at $7.5 \mathrm{~K}$. The last data point corresponds to decomposition of $65 \%$ of $\mathrm{HCN}$.

In order to describe LIF kinetics properly, a number of factors should be considered, being extremely difficult to do in practice. First, rare-gas solids can often not be regarded as optically thin, and the depletion of the excitation field during its penetration into the matrix layer plays an important role in quantitative kinetics studies [63,67,99-101]. If a sample contains a sufficient number of precursor molecules, photogenerated new species can essentially absorb the photolysis radiation and hence decrease strongly the photolysis efficiency for deeper matrix layers. Hence the in situ-detected LIF signal of the photogenerated species saturates faster than their averaged concentration does [63]. This effect was also qualitatively discussed by Gödderz et al. [102].

The second factor strongly influencing LIF kinetics is introduced by photogenerated species that are capable of absorbing the detected emission. This process can change the detected LIF spectra from different matrix depths strongly thereby introducing an additional error between the LIF and true kinetics. One example of rising absorbers is provided by a charge-transfer mechanism known for species like oxygen, iodine, etc. in rare-gas solids $[99,100,103]$. The extraordinary disappearance of one emission band in the NO progression generated in the 193-nm photolysis of $\mathrm{HNCO} / \mathrm{Xe}$ matrices was explained by considering a charge-transfer absorption [67].

Finally, Rayleigh scattering enhances the two above-mentioned mechanisms because it increases the path length of radiation in the sample and limits 
penetration of the radiation into the deeper matrix layers even if the matrix absorption is rather weak. Even alone, Rayleigh scattering destroys the ideal one-exponential photolysis kinetics for concentration due to spatial redistribution of radiation intensity [63].

Intrinsic properties. Until recently, the $\mathrm{HXY}$ molecules have been prepared in solid rare gases, mainly $\mathrm{Kr}$ and Xe. Since the molecules are strongly polar there arises the question of their intrinsic stability and of the stabilization effect of the polarizable hosts. To address this question of intrinsic stability, photolysis of $\mathrm{HBr}$ and $\mathrm{HCl}$ in Xe-doped neon matrices was performed [104]. Quite surprisingly, even at very high dilution mobilization of $\mathrm{H}$ atoms in $\mathrm{Ne}$ at $\sim 9-10 \mathrm{~K}$ resulted in new absorptions at wavenumbers similar to the $\mathrm{v}(\mathrm{Xe}-\mathrm{H})$ of $\mathrm{HXeBr}$ and $\mathrm{HXeCl}$ in pure Xe matrices. These absorptions showed proper deuteration shifts for $\mathrm{HXeBr}$ and $\mathrm{HXeCl}$, and the species responsible could be photodecomposed similarly to $\mathrm{HXeBr}$ and $\mathrm{HXeCl}$ in $\mathrm{Xe}$. Based on these facts the forming molecules were identified as $\mathrm{HXeBr}$ and $\mathrm{HXeCl}$ in a Ne surrounding. This result shows experimentally the intrinsic stability of the HXY species supporting the computational results, and suggest for their existence also in the gas phase. The $v(\mathrm{Xe}-\mathrm{H})$ wavenumbers of $\mathrm{HXeCl}$ and $\mathrm{HXeBr}$ in solid $\mathrm{Ne}$ are shifted about $50 \mathrm{~cm}^{-1}$ downwards from the values reported in Xe [56]. This shift can be considered to measure the stabilization effect of the solid Xe environment.

\section{Conclusions}

Solid state photochemical production of several $\mathrm{Kr}$ and Xe hydrides is described, and the IR spectra of these molecules are given. For aiding the experimental interpretation, extensive ab initio calculations were performed. Computationally, the formation of these hydrides decreases, for example, the $\mathrm{Rg}-\mathrm{H}$ distance by more than a factor of two from its van der Waals value.

These $\mathrm{HKrY}$ and $\mathrm{HXeY}$ molecules possess both covalent and ionic contributions in the bonding, and their dipole moments are quite large. The extensive charge-transfer nature of these molecules is evidenced also by the strong $\mathrm{Rg}-\mathrm{H}$ stretching vibrations both computationally and experimentally. These hydrides are produced in low temperature matrices by photodissociation of a hydrogen-containing precursor and thermal mobilization of photodetached hydrogen atom. The estimated dissociation energies vary from 0.4 to $1.4 \mathrm{eV}$, and warrant observation of these molecules also in the gas phase.
The photolysis of small hydrides in solid $\mathrm{Xe}$ seems to be a quite local process, and losses of $\mathrm{H}$ atoms play a minor role. The controversial estimates of the light-induced travel distances can originate from an improper treatment of LIF data. The effects of matrix optics become more important for shorter photolysis / LIF wavelengths due to Rayleigh scattering, and in particular they might be deeply problematic in vacuum UV experiments. As a qualitative conclusion of practical importance for matrixisolation studies, matrix optics should be taken into account while extracting numerical dissociation parameters from LIF kinetics. In fact, FTIR measurements provide more reliable data for such a quantitative analysis.

1. L. Pauling, J. Am. Chem. Soc. 55, 1895 (1933).

2. N. Bartlett, Proc. Chem. Soc. 218 (1962).

3. F. O. Sladky, P. A. Bulliner, and N. Bartlett, J. Chem. Soc. A2179 (1969).

4. R. Hoppe, W. Dähne, H. Mattauch, and K. H. Rödder, Angew. Chem. 74, 903 (1962).

5. H. H. Claassen, H. Selig, and J. G. Malm, J. Am. Chem. Soc. 84, 3593 (1962)

6. J. R. Morten and W. E. Falconer, J. Chem. Phys. 39, 427 (1963).

7. E. Tommila, Suomen Kemistilehti A36, 209 (1963).

8. J. G. Malm, H. Selig, J. Jortner, and S. A. Rice, Chem. Rev. 65, 199 (1965).

9. F. O. Sladky, P. A. Bulliner, N. Bartlett, B. G. DeBoer, and A. Zankin, Chem. Commun. 1048 (1968).

10. V. M. McRae, R. D. Peacock, and D. R. Russell, Chem. Commun. 62 (1969).

11. J. H. Holloway and J. G. Knowles, J. Chem. Soc. A756 (1969).

12. N. Bartlett, M. Gennis, D. D. Gibler, B. K. Morrell, and A. Zalkin, Inorg. Chem. 12, 1717 (1973).

13. D. E. McKee, C. J. Adams, and N. Bartlett, Inorg. Chem. 12, 1722 (1973)

14. N. Bartlett and F. O. Sladky, Comprehensive Inorganic Chemistry, Pergamon Press, New York (1973), vol 3, p. 213.

15. K. Seppelt and D. Lentz, Prog. Inorg. Chem. 29, 167 (1982).

16. J. H. Holloway, J. Fluor. Chem. 33, 149 (1986).

17. C. A. Coulson, J. Chem. Soc. 1442 (1964).

18. R. D. LeBlond and D. D. DesMarteau, J. Chem. Soc. Chem. Commun. 555 (1974).

19. D. D. DesMarteau, J. Am. Chem. Soc. 100, 6270 (1978).

20. D. D. DesMarteau, R. D. LeBlond, S. F. Hossain, and D. Nothe, J. Am. Chem. Soc. 103, 7734 (1981).

21. A. A. A. Emara and G. J. Schrobilgen, J. Chem. Soc. Chem. Commun. 1644 (1987).

22. A. A. A. Emara and G. J. Schrobilgen, J. Chem. Soc. Chem. Commun. 257 (1988).

23. G. J. Schrobilgen, J. Chem. Soc. Chem. Commun. 1506 (1988).

24. J. Foropopoulos, Jr. and D. D. DesMarteau, J. Am. Chem. Soc. 104, 4260 (1982).

25. J. F. Sawyer, G. J. Schrobilgen, and S. J. Sutherland, Inorg. Chem. 21, 4064 (1982).

26. G. A. Schumacher and G. J. Schrobilgen, Inorg. Chem. 22, 2178 (1983) 
27. R. Faggiani, D. K. Kennepohl, C. J. L. Lock, and G. J. Schrobilgen, Inorg. Chem. 25, 563 (1986).

28. M. Wechsberg, P. A. Bulliner, F. O. Sladky, R. Mews, and N. Bartlett, Inorg. Chem. 11, 3063 (1972).

29. L. J. Turbini, R. E. Aikman, and R. J. Lagow, J. Am. Chem. Soc. 101, 5833 (1979).

30. D. Naumann and W. Tyrra, J. Chem. Soc. Chem. Commun. 47 (1989).

31. V. V. Zhdankin, P. J. Stang, and N. S. Zefirov, J. Chem. Soc. Chem. Commun. 578 (1992).

32. D. Naumann, W. Tyrra, R. Gnann, D. Pfolk, T. Gilles, and K. F. Tebbe, Z. Anorg. Allg. Chem. 623, 1821 (1997).

33. H. J. Frohn, N. LeBlond, K. Lutar, and B. Zemva, Angew. Chem. Int. Ed. 39, 391 (2000).

34. J. H. Holloway and E. G. Hope, in: Advances in Inorganic Chemistry, Academic Press, London (1999), vol 46, p. 51.

35. J. J. Turner and G. C. Pimentel, Science 140, 975 (1963).

36. D. R. MacKenzie, Science 141, 1171 (1963).

37. W. F. Howard and L. Andrews, J. Am. Chem. Soc. 96, 7864 (1974).

38. A. V. Grosse, A. D. Kirschenbaum, A. G. Streng, and L. V. Streng, Science 139, 1047 (1963).

39. G. J. Schrobilgen, J. Chem. Soc. Chem. Commun. 863 (1988).

40. J. C. P. Sanders and G. J. Schrobilgen, J. Chem. Soc. Chem. Commun. 1576 (1989).

41. R. J. Gillespie and G. J. Schrobilgen, Inorg. Chem. 15, 22 (1976).

42. G. J. Schrobilgen, J. Chem. Soc. Chem. Commun. 1506 (1988).

43. G. Frenking and D. Cremer, in: Structure and Bonding, Noble Gas and High Temperature Chemistry, M. J. Clarke et al. (ed.), Springer, Berlin (1990), p. 17.

44. G. J. Schrobilgen, in: Synthetic Fluorine Chemistry, G. A. Olah, R. D. Chambers, G. K. Surya Prakash (eds.) John Wiley and Sons, New York (1992).

45. I. Last and T. F. George, in: Cluster Ions, C. Y. Ng, T. Baer, and I. Powis (eds.), John Wiley and Sons, New York (1993) and References therein

46. M. Beyer, E. V. Savchenko, G. Niedner-Schatteburg, and V. E. Bondybey, J. Chem. Phys. 110, 11910 (1999).

47. P. Pyykkö, Eur. J. Chem. (2000) (in press).

48. E. Whittle, D. A. Dows, and G. C. Pimentel, J. Chem. Phys. 22, 1943 (1954).

49. I. Norman and G. O. Porter, Nature 174, 508 (1954).

50. H. Broida and J. R. Pellam, Phys. Rev. 95, 845 (1954).

51. L. Y. Nelson and G. C. Pimentel, Inorg. Chem. 6, 1758 (1967).

52. V. E. Bondybey, Doct. Thesis, Univ. of California (1971).

53. C. T. Goetschel and K. R. Loos, J. Am Chem. Soc. 94, 3018 (1972).

54. V. A. Apkarian and N. Schwentner, Chem. Rev. 99, 1481 (1999).

55. V. E. Bondybey, M. Räsänen, and A. Lammers, Annu. Rep. Prog. Chem. Sect. C95, 331 (1999).

56. M. Pettersson, J. Lundell, and M. Räsänen, J. Chem. Phys. 102, 6423 (1995).

57. M. Pettersson, J. Lundell, and M. Räsänen, J. Chem. Phys. 103, 205 (1995).

58. M. Pettersson, J. Nieminen, L. Khriachtchev, and M. Räsänen, J. Chem. Phys. 107, 8423 (1997).

59. M. Pettersson, J. Lundell, L. Khriachtchev, and $M$. Räsänen, J. Chem. Phys. 109, 618 (1998).

60. M. Pettersson, J. Lundell, L. Khriachtchev, E. Isoniemi, and M. Räsänen, J. Am. Chem. Soc. 7979 (1998).
61. M. Pettersson and J. Nieminen, Chem. Phys. Lett. 283, 1 (1997).

62. M. Pettersson, Doct. Thesis, University of Helsinki (1998).

63. L. Khriachtchev, M. Pettersson, and M. Räsänen, Chem. Phys. Lett. 288, 727 (1998).

64. M. Pettersson, L. Khriachtchev, J. Lundell, and M. Räsänen, J. Am. Chem. Soc. 121, 11904 (1999).

65. M. Pettersson, J. Lundell, and M. Räsänen, Eur. J. Inorg. Chem. 729 (1999).

66. L. Khriachtchev, M. Pettersson, S. Pehkonen, E. Isoni emi, and M. Räsänen, J. Chem. Phys. 111, 1650 (1999).

67. L. Khriachtchev, M. Pettersson, S. Jolkkonen, and M. Räsänen, Chem. Phys. Lett. 316, 115 (2000).

68. M. Pettersson, L. Khriachtchev, J. Lundell, S. Jolkkonen, and M. Räsänen, J. Phys. Chem. A104, 3579 (2000).

69. M. Pettersson, L. Khriachtchev, J.-R. Roozeman, and M. Räsänen, Chem. Phys. Lett. 323, 506 (2000).

70. N. Runeberg, M. Seth, and P. Pyykkö, Chem. Phys. Lett. 246, 239 (1995).

71. N. Runeberg, Doct. Thesis, University of Helsinki (1996).

72. R. W. Bickes, Jr., B. Lantzsch, J. P. Toennies, and K. Walaschewski, Farad. Discuss. Chem. Soc. 55, 167 (1973).

73. W. C. Lane, T. H. Edwards, J. R. Gillis, E. S. Bonomo, and F. J. Murcray, J. Mol. Spectrosc. 95, 365 (1982).

74. J. Lundell, M. Pettersson, and M. Räsänen, Computers and Chemistry 24, 325 (2000).

75. N. Franks and W. R. Lieb, Nature 367, 607 (1994).

76. N. Bartlett, M. Wechsberg, G. R. Jones, and R. D. Burbank, Inorg. Chem. 11, 1124 (1972).

77. I. Last and T. F. George, J. Chem. Phys. 89, 3071 (1988).

78. J. W. C. Johns, J. Mol. Spectrosc. 106, 124 (1984).

79. H. E. Warner, W. T. Connor, and R. C. Woods, J. Chem. Phys. 81, 5413 (1984).

80. R. Klein and P. Rosmus, Z. Naturforsch. 39A, 349 (1984).

81. K. A. Peterson, R. H. Petrmichl, R. L. McClain, and R. C. Woods, J. Chem. Phys. 95, 2352 (1991).

82. S. A. Rogers, C. R. Brazier, and P. F. Bernath, J. Chem. Phys. 87, 159 (1987).

83. S. Berski, B. Silvi, J. Lundell, S. Noury, and Z. Latajka, in: Progress in Theoretical Chemistry and Physics, C. Minot et al. (eds.), Kluwer, Amsterdam (2000) (in press).

84. M. Johansson, M. Hotokka, M. Pettersson, and M. Räsänen, Chem. Phys. 244, 25 (1999).

85. J. Lundell, G. M. Chaban, and R. B. Gerber, J. Phys. Chem. B104 (2000) (in press).

86. M. Lorenz, D. Kraus, M. Räsänen, and V. E. Bondybey, $J$. Chem. Phys. 112, 3803 (2000).

87. H.Okabe, Photochemistry of Small Molecules, Wiley, New York (1978).

88. D. LaBrake, E. T. Ryan, and E. Weitz, J. Chem. Phys. 102, 4112 (1995).

89. H. Muto, K. Nunome, and M. Iwasaki, J. Phys. Chem. 84, $3402(1980)$.

90. D. LaBrake and E. Weitz, Chem. Phys. Lett. 211, 430 (1993).

91. V. I. Feldman and F. F. Sukhov, Chem. Phys. Lett. 255, 425 (1996).

92. V. I. Feldman, F. F. Sukhov, and A. Yu. Orlov, Chem. Phys. Lett. 280, 507 (1997).

93. J. Eberlein and M. Creutzburg, J. Chem. Phys. 106, 2188 (1997) and References therein.

94. J. Lundell, M. Pettersson, L. Khriachtchev, M. Räsänen, G. M. Chaban, and R. B. Gerber, Chem. Phys. Lett. 322, $389(2000)$.

95. R. Alimi, R. B. Gerber, and V. A. Apkarian, J. Chem. Phys. 89, 174 (1988). 
96. R. Alimi and R. B. Gerber, Chem. Phys. Lett. 173, 393 (1990).

97. J. Eloranta, K. Vaskonen, and H. Kunttu, J. Chem. Phys. 110, 7917 (1999).

98. T. Kiljunen, J. Eloranta, and H. Kunttu, J. Chem. Phys. 110, 11814 (1999).

99. M. E. Fajardo and V. A. Apkarian, J. Chem. Phys. 85, 5660 (1986).

100. M. E. Fajardo and V. A. Apkarian, J. Chem. Phys. 89, 4102 (1988).
101. J. R. Sheats, J. J. Diamond, and J. M. Smith, J. Phys. Chem. 92, 4922 (1988).

102. K. H. Godderz, N. Schwentner, and M. Chergui, J. Chem. Phys. 105, 451 (1996) and References therein.

103. W. G. Lawrence and V. A. Apkarian, J. Chem. Phys. 97, 2229 (1992)

104. M.Lorenz, M. Räsänen, and V. E. Bondybey, J. Phys. Chem. A104, 3770 (2000). 